\title{
Development of variously functionalized nitrile oxides
}

\author{
Haruyasu Asahara $^{* 1,2}$, Keita Arikiyo ${ }^{1}$ and Nagatoshi Nishiwaki ${ }^{* 1,2}$
}

\author{
Full Research Paper \\ Address: \\ ${ }^{1}$ School of Environmental Science and Engineering, Kochi University \\ of Technology, Tosayamada, Kami, Kochi 782-8502, Japan and \\ ${ }^{2}$ Research Center for Material Science and Engineering, Kochi \\ University of Technology, Tosayamada, Kami, Kochi 782-8502, Japan

\section{Email:} \\ Haruyasu Asahara* - asahara.haruyasu@kochi-tech.ac.jp; \\ Nagatoshi Nishiwaki* - nishiwaki.nagatoshi@kochi-tech.ac.jp \\ * Corresponding author \\ Keywords: \\ acylnitrile oxide; amide; formylnitrile oxide; functionalized nitrile oxide; \\ Weinreb amide
}

\author{
Beilstein J. Org. Chem. 2015, 11, 1241-1245. \\ doi:10.3762/bjoc. 11.138 \\ Received: 13 May 2015 \\ Accepted: 16 July 2015 \\ Published: 23 July 2015 \\ Associate Editor: R. Sarpong \\ (C) 2015 Asahara et al; licensee Beilstein-Institut. \\ License and terms: see end of document.
}

\begin{abstract}
$\mathrm{N}$-Methylated amides ( $\mathrm{N}, 4$-dimethylbenzamide and $\mathrm{N}$-methylcyclohexanecarboxamide) were systematically subjected to chemical transformations, namely, $N$-tosylation followed by nucleophilic substitution. The amide function was converted to the corresponding carboxylic acid, esters, amides, aldehyde, and ketone upon treatment with hydroxide, alkoxide, amine, diisobutylaluminium hydride and Grignard reagent, respectively. In these transformations, $N$-methyl- $N$-tosylcarboxamides behave like a Weinreb amide. Similarly, $N$-methyl-5-phenylisoxazole-3-carboxamide was converted into 3-functionalized isoxazole derivatives. Since the amide was prepared by the cycloaddition reaction of ethynylbenzene and $N$-methylcarbamoylnitrile oxide, the nitrile oxide served as the equivalent of the nitrile oxides bearing a variety of functional groups such as carboxy, alkoxycarbonyl, carbamoyl, acyl and formyl moieties.
\end{abstract}

\section{Introduction}

Nitrile oxides are valuable synthetic synthons for the construction of heterocyclic compounds by cycloaddition reactions, which lead to the formation of two bonds in a single experimental step [1,2]. In addition, cycloadducts serve as precursors of polyfunctionalized compounds by ring opening reaction followed by $\mathrm{N}-\mathrm{O}$ bond fission $[2,3]$. Hence, functionalized nitrile oxides are clearly useful for the preparation of more complex systems. However, because the precursors of the functionalized nitrile oxides are not always easily available, there are only a few reports that deal with these compounds compared to those on alkylated and arylated nitrile oxides [1]. Thus, it is highly desirable to develop methodologies for the facile generation of functionalized nitrile oxides.

In our previous work, we reported the preparation of nitrile oxide 2 bearing an $N$-methylcarbamoyl group by treatment of 2-methyl-4-nitroisoxazolin-5(2H)-one (1) only with water at room temperature. Nitrile oxide $\mathbf{2}$ undergoes cycloaddition reactions with alkenes [4,5], alkynes (Scheme 1) [4,5], nitriles [6], and 1,3-dicarbonyl compounds [7] to afford the corresponding polyfunctionalized heterocyclic compounds, which are not easily obtained by other approaches. Although this protocol is 


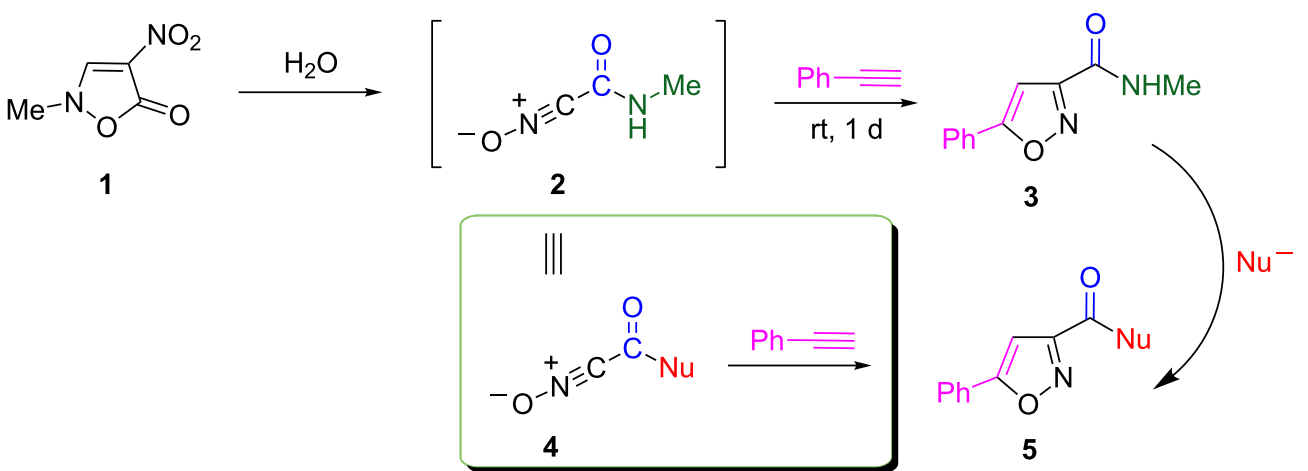

Scheme 1: A strategy for developing functionalized nitrile oxides.

expected to be useful for synthesizing polyfunctionalized compounds, it is limited by the need of a $N$-methylcarbamoyl functional group. The synthetic utility of nitrile oxide 2 will be indeed improved by converting the $N$-methylcarbamoyl group into other functionalities, i.e., nitrile oxide $\mathbf{2}$ may serve as an equivalent of nitrile oxides $\mathbf{4}$ having versatile functional groups (Scheme 1).

Weinreb amide ( $N$-methoxy- $N$-methylamide) is widely used for the conversion of less reactive amide moieties into other carbonyl functionalities $[8,9]$. The two oxygen atoms of the methoxy and carbonyl groups coordinate to the organometallic reagents, thereby suppressing further reaction with the obtained aldehyde or ketone. However, this protocol cannot be applied to the conversion of $N$-methylamides because methoxylation of $N$-methylamides is hitherto unknown. Thus, we speculated that the introduction of a sulfonyl group would be effective because of its high electron-withdrawing and coordinating abilities, serving as an equivalent of the Weinreb amide. Indeed, the use of $\mathrm{N}$-methyl-3-phenyl- $N$-tosylbutanamide for this purpose was already reported by Itoh and coworkers [10]. However, a systematic study using simple amides has not yet been performed. In this context, we examined the sulfonylation and chemical conversion of $N$-methylated aromatic and aliphatic amides, and a similar conversion of $N$-methyl-5-phenylisoxazole-3-carboxamide (3), which is equal to the generation of variously functionalized nitrile oxides.

\section{Results and Discussion}

At the outset, methanesulfonylation (mesylation) of amides was studied. To a suspension of $N, 4$-dimethylbenzamide $(\mathbf{6 A})$ and sodium hydride ( 2 equiv) in THF, mesyl chloride (7a, 1.3 equiv) was added, and the resultant mixture was stirred at room temperature for $9 \mathrm{~h}$. After acidification, the reaction mixture was extracted with diethyl ether to afford the crude material, from which $32 \%$ of $N$-mesylated product 8Aa [11] was isolated and $61 \%$ of $6 \mathrm{~A}$ was recovered. Thus, the conversion yield of 8 Aa was $82 \%$ (Table 1, entry 1). On the other hand, the yield of 8Aa was considerably increased (up to 70\%) when ethylmagnesium bromide was employed as a base instead of

Table 1: Sulfonylation of $\mathrm{N}$-methylamides.

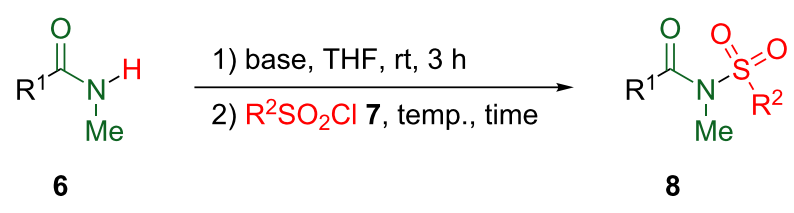

\begin{tabular}{|c|c|c|c|c|c|c|c|}
\hline entry & $\mathrm{R}^{1}$ & $\mathrm{R}^{2}$ & Base (equiv) & Temp. $/{ }^{\circ} \mathrm{C}$ & Time/h & Product & Yield $/ \%$ \\
\hline 1 & $4-\mathrm{MeC}_{6} \mathrm{H}_{4}$ & $\mathrm{Me}$ & $\mathrm{NaH}(2)$ & $\mathrm{rt}$ & 9 & $8 A a$ & $32(82)^{a}$ \\
\hline 2 & $4-\mathrm{MeC}_{6} \mathrm{H}_{4}$ & $\mathrm{Me}$ & EtMgBr (1.1) & 0 & 1 & $8 \mathrm{Aa}$ & 70 \\
\hline 3 & $4-\mathrm{MeC}_{6} \mathrm{H}_{4}$ & $4-\mathrm{MeC}_{6} \mathrm{H}_{4}$ & $\mathrm{NaH}(2)$ & 0 & 24 & $8 A b$ & $60(92)^{2}$ \\
\hline 4 & c-Hexyl & $4-\mathrm{MeC}_{6} \mathrm{H}_{4}$ & $\mathrm{NaH}(2)$ & 0 & 12 & $8 \mathrm{Bb}$ & 38 \\
\hline $5^{b}$ & $c$-Hexyl & $4-\mathrm{MeC}_{6} \mathrm{H}_{4}$ & $\mathrm{NaH}(2)$ & 0 & 12 & $8 \mathrm{Bb}$ & $60(85)^{2}$ \\
\hline
\end{tabular}

${ }^{a}$ Conversion yields were shown in parentheses; ${ }^{b} 5$ equivalents of $7 \mathbf{b}$ were used. 
sodium hydride (Table 1 , entry 2 ). However, the instability and gradual decomposition of mesylated product $\mathbf{8 A a}$ by ambient moisture impedes its storage and use as a synthetic reagent. Hence, in the place of the mesyl group, the 4-methylbenzenesulfonyl (tosyl) moiety was employed as the activating group of the amide function. Indeed, tosylated product 8Ab [11] proved to be sufficiently stable under ambient conditions. Despite the considerable efforts for optimizing the reaction conditions, the highest yield obtained for $\mathbf{8 A b}$ was $60 \%$; however, $35 \%$ of starting material 6A was recovered, and the conversion yield was $92 \%$. This tosylation method was applied to the aliphatic amide $N$-methylcyclohexanecarboxamide $(6 \mathbf{B})$ to afford $\mathbf{8 B b}$ upon treatment with tosyl chloride $(\mathbf{7 b})$ using sodium hydride as a base (Table 1, entry 4). In this case, the use of an excess of $\mathbf{7 b}$ increased the yield of $\mathbf{8 B b}$ up to $60 \%$ (85\% of conversion yield, Table 1, entry 5).

Next, nucleophilic substitutions of tosylated amides $\mathbf{8 A \mathbf { b }}$ and $\mathbf{8 B b}$ were investigated (Table 2). Whereas water and methanol did not alter the amide moieties, hydroxide and methoxide converted amides $\mathbf{8 A \mathbf { b }}$ and $\mathbf{8 B \mathbf { b }}$ into the corresponding carboxylic acids (9a and 10a) and methyl esters (9b and 10b), respectively (Table 2, entries $1-4$ ). In addition, the nucleophilic substitution also proceeded by employing neutral amines. The reaction of $\mathbf{8}$ with propylamine proceed smoothly, leading to $N$-propylamides 9c and 10c (Table 2, entries 5 and 6). The substitution reaction was influenced by the bulkiness of the amines. Heating at $120{ }^{\circ} \mathrm{C}$ was required for the substitution reaction by sec-butylamine. However, in the case of tert-butylamine, even when the reaction was conducted in a sealed tube at $120^{\circ} \mathrm{C}$, only a small amount of amide was observed (Table 2, entries 7-10). On the other hand, a cyclic secondary amine, pyrrolidine, afforded amides 9 f and 10 quantitatively at room temperature (Table 2, entries 11 and 12).

When more reactive butyllithium or isopropylmagnesium bromide was used as the nucleophile, the corresponding tertiary alcohols $11 \mathrm{~g}$ and $11 \mathrm{~h}$ were obtained in $51 \%$ and $58 \%$ yields, respectively, whereas ketones $\mathbf{9 g}$ and $\mathbf{9 h}$ were not detected (Table 2, entries 13 and 14). In the case of an aromatic Grignard reagent, the undesired reaction was suppressed. Although the reaction did not occur at $-78^{\circ} \mathrm{C}$, the substitution proceeded successfully at $-40{ }^{\circ} \mathrm{C}$, affording ketones $9 \mathbf{i}$ and $\mathbf{1 0 i}$ (Table 2, entries 15 and 16). Sodium borohydride also proved to be

Table 2: Chemical conversions of $N$-methylamide to other functions.

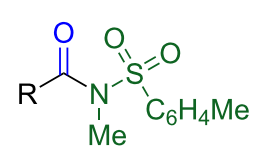

$\mathrm{R}=4-\mathrm{MeC}_{6} \mathrm{H}_{4} \mathbf{8 A b}$ cyclohexyl $\mathbf{8 B b}$

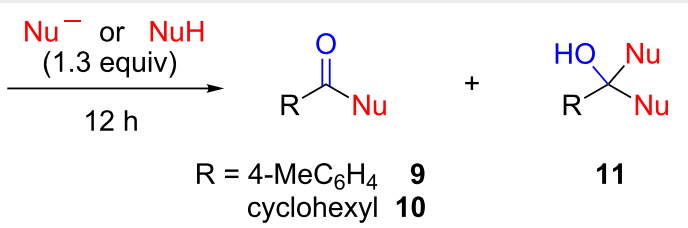
cyclohexyl 10

\begin{tabular}{|c|c|c|c|c|c|c|}
\hline entry & Amide & Nucleophile & Solvent & Temp. $/{ }^{\circ} \mathrm{C}$ & Product & Yield $/ \%$ \\
\hline 1 & $8 A b$ & $\mathrm{NaOH}$ & $\mathrm{H}_{2} \mathrm{O}$ & 85 & $9 a$ & quant. \\
\hline 2 & $8 B b$ & $\mathrm{NaOH}$ & $\mathrm{H}_{2} \mathrm{O}$ & 85 & $10 a$ & 94 \\
\hline 3 & $8 \mathrm{Ab}$ & $\mathrm{NaOMe}$ & $\mathrm{MeOH}$ & 60 & $9 b$ & 62 \\
\hline 4 & $8 B b$ & $\mathrm{NaOMe}$ & $\mathrm{MeOH}$ & 60 & $10 \mathrm{~b}$ & 73 \\
\hline 5 & $8 A b$ & $\mathrm{PrNH}_{2}$ & THF & $\mathrm{rt}$ & $9 c[12]$ & quant. \\
\hline 6 & $8 B b$ & $\mathrm{PrNH}_{2}$ & THF & $\mathrm{rt}$ & $10 c$ & 82 \\
\hline 7 & $8 A b$ & sec-BuNH 2 & THF & 120 & $9 d[13]$ & 72 \\
\hline 8 & $8 B b$ & sec-BuNH${ }_{2}$ & THF & 120 & $10 d$ & 79 \\
\hline 9 & $8 A b$ & tert-BuNH${ }_{2}$ & THF & 120 & $9 e[14]$ & 19 \\
\hline 10 & $8 \mathrm{Bb}$ & tert-BuNH 2 & THF & 120 & $10 \mathrm{e}[15]$ & 3 \\
\hline 11 & $8 A b$ & pyrrolidine & THF & $\mathrm{rt}$ & 9f [16] & quant. \\
\hline 12 & $8 B b$ & pyrrolidine & THF & rt & $10 f[17]$ & quant. \\
\hline 13 & $8 A b$ & BuLi & THF & -78 & $9 g$ & $0(51)^{a}$ \\
\hline 14 & $8 A b$ & $\mathrm{iPrMgBr}$ & THF & -40 & $9 \mathrm{~h}$ & $0(58)^{a}$ \\
\hline 15 & $8 A b$ & 4-MeOC $6 \mathrm{H}_{4} \mathrm{MgBr}$ & THF & -40 & $9 i[18]$ & 59 \\
\hline 16 & $8 B b$ & 4- $\mathrm{MeOC}_{6} \mathrm{H}_{4} \mathrm{MgBr}$ & THF & -40 & $10 \mathrm{i}[19]$ & 33 \\
\hline 17 & $8 A b$ & $\mathrm{NaBH}_{4}$ & THF & -78 & $9 \mathrm{j}$ & $0(64)^{a}$ \\
\hline 18 & $8 A b$ & $\mathrm{iBu}_{2} \mathrm{AlH}$ & THF & -78 & $9 j$ & $77(12)^{a}$ \\
\hline 19 & $8 \mathrm{Bb}$ & $\mathrm{iBu}_{2} \mathrm{AlH}$ & THF & -78 & $10 \mathrm{j}$ & 39 \\
\hline
\end{tabular}

antermediately produced 9 or 10 underwent the excess reactions to afford alcohols 11. 
highly reactive, causing a further addition reaction even at $-78{ }^{\circ} \mathrm{C}$ to generate the corresponding alcohol $\mathbf{1 1 j}$ (Table 2, entry 17). This disadvantage was overcome by using bulkier diisobutylaluminium hydride (DIBAL) to furnish aldehydes $\mathbf{9 j}$ and $\mathbf{1 0 j}$, although small amounts of alcohol $\mathbf{1 1} \mathbf{j}$ were also detected (Table 2, entries 18 and 19).

In contrast to tosylated amides $\mathbf{8 A \mathbf { A }}$ and $\mathbf{8 B \mathbf { b }}$, tosylated $\mathrm{N}$-methyl-5-phenylisoxazole-3-carboxamide $\mathbf{1 2}$ exhibited higher reactivity. Upon tosylation under similar conditions 3 did not afford product 12, and isoxazole-3-carboxylic acid 5a, a hydrolyzed product of $\mathbf{1 2}$, was observed. This problem was solved by quenching the reaction mixture with ice water instead of just water; yet, 12 was afforded in only $10 \%$ yield, and 5a was the main product in $38 \%$ yield. These findings imply that during the work-up procedure, further decomposition of $\mathbf{1 2}$ by water occurred even at low temperatures because of the higher electron deficiency of the isoxazole ring compared with carbocyclic rings. When, instead of water, less nucleophilic acetic acid was employed for the quench, 12 was isolated in 74\% yield and the competitive hydrolysis of $\mathbf{1 2}$ was suppressed (6\% of 5a).

Although tosylated amide $\mathbf{1 2}$ could be isolated, it gradually decomposed under ambient conditions. Hence, the chemical conversion was performed by adding a nucleophile to the mixture of the tosylation reaction, without the isolation of $\mathbf{1 2}$ (Table 3). As mentioned above, the use of a hydroxide anion for the hydrolysis was not required, and carboxylic acid 5a was obtained in $81 \%$ yield by the addition of only water (Table 3 , entry 1). This protocol was applicable to a relatively bulky alcohol to afford isopropyl ester $\mathbf{5 k}$ in moderate yield (Table 3, entry 2). Similarly, primary and secondary amines underwent the substitution reaction, leading to $\mathbf{5 c - f}$ in good to moderate yields (Table 3, entries 3-6). It was noteworthy that, because of high reactivity of 12 caused by the isoxazole ring [20], the methylamino group could be replaced by a bulky tert-butylamino moiety. Conversion of the $N$-methylcarbamoyl group to an acyl or formyl group was achieved upon treatment with a Grignard reagent or with DIBAL (Table 3, entries 7 and 8).

The chemical conversion of $N$-methylamides to versatile carbonyl functions was systematically studied. In this protocol, the tosyl group was found to be effective for the activation of the carbamoyl group and for preventing over-addition by organometallic reagents. Isoxazole-3-carboxamide $\mathbf{3}$ was successfully converted in a similar fashion. Thus, as shown in Figure 1, nitrile oxide $\mathbf{2}$ serves as an equivalent of functionalized nitrile oxides 4 , thereby improving the synthetic utility of carbamoylnitrile oxide 2 .
Table 3: Chemical conversion of $N$-methylisoxazole-3-carboxamide 3.

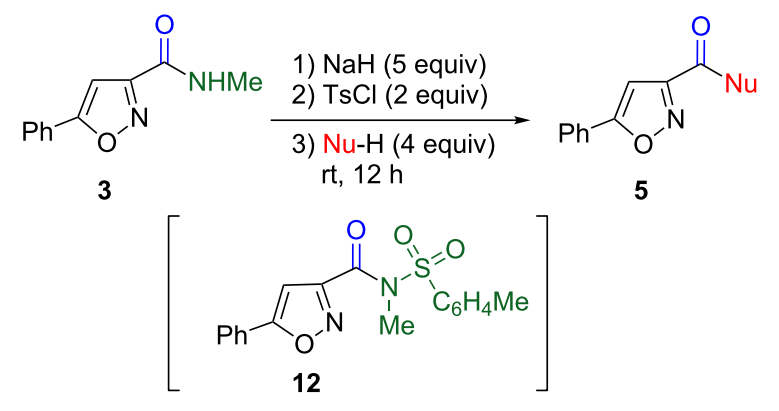

\begin{tabular}{|c|c|c|c|}
\hline entry & $\mathrm{Nu}-\mathrm{H}$ & & Yield/\% \\
\hline 1 & $\mathrm{OH}_{2}$ & $5 a[21]$ & 81 \\
\hline 2 & iPrOH & $5 \mathbf{k}[22]$ & 59 \\
\hline 3 & $\mathrm{PrNH}_{2}$ & $5 c$ [23] & 74 \\
\hline 4 & sec-BuNH 2 & 5d [22] & 59 \\
\hline 5 & tert-BuNH${ }_{2}$ & $5 e[24]$ & 30 \\
\hline 6 & pyrrolidine & $5 f[23]$ & 42 \\
\hline $7^{a, b}$ & $\begin{array}{l}\text { 4-MeOC } 6 \mathrm{H}_{4} \\
\mathrm{MgBr}\end{array}$ & 5i [25] & 45 \\
\hline $8^{a, c}$ & $\mathrm{iBu}_{2} \mathrm{AlH}$ & 5j [26] & 40 \\
\hline
\end{tabular}

a 2 Equiv of nucleophiles were used. ${ }^{\mathrm{b}} \mathrm{At}-40^{\circ} \mathrm{C}$. ${ }^{\mathrm{c}} \mathrm{At}-78^{\circ} \mathrm{C}$.

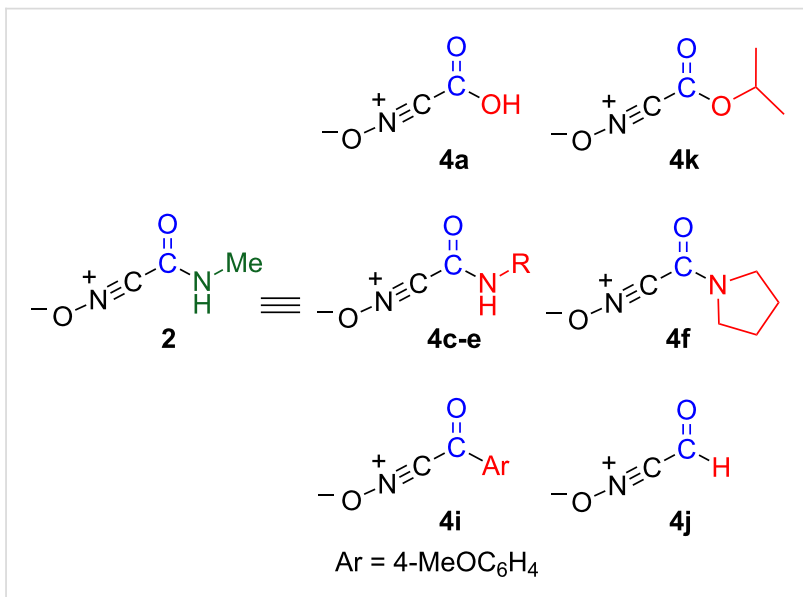

Figure 1: Versatile functionalized nitrile oxides.

\section{Experimental Conversion of isoxazolecarboxamide 3 to $5 \mathrm{c}$ via tosyl derivative 12}

To a solution of amide 3 (101 mg, $0.5 \mathrm{mmol})$ in THF ( $1 \mathrm{~mL})$, a suspension of $60 \mathrm{wt} \%$ sodium hydride $(100 \mathrm{mg}, 2.5 \mathrm{mmol})$ in THF ( $3 \mathrm{~mL}$ ) was added under argon. After the mixture was stirred vigorously for $10 \mathrm{~min}$, the mixture was cooled to $0{ }^{\circ} \mathrm{C}$ and then a solution of tosyl chloride (191 mg, $1 \mathrm{mmol})$ in THF $(1 \mathrm{~mL})$ was slowly added. After the mixture was stirred for $3 \mathrm{~h}$ at $0{ }^{\circ} \mathrm{C}$, propylamine $(164 \mu \mathrm{L}, 2 \mathrm{mmol})$ was added, and then the mixture was stirred at room temperature for $12 \mathrm{~h}$. After evapor- 
ation of the solvent, the residue was dissolved into diethyl ether $(5 \mathrm{~mL})$, washed with water $(5 \mathrm{~mL})$, and the aqueous layer was extracted with diethyl ether $(2 \times 5 \mathrm{~mL})$. The combined organic layer was dried over magnesium sulfate, and concentrated, and the residue was subjected to column chromatography on silica gel to afford $N$-propylcarboxamide 5c $(85 \mathrm{mg}, 0.37 \mathrm{~mol}, 74 \%$ yield), eluted with dichloromethane. ${ }^{1} \mathrm{H}$ NMR $(400 \mathrm{MHz}$, $\left.\mathrm{CDCl}_{3}, \mathrm{TMS}\right) \delta 1.01(\mathrm{t}, J=7.2 \mathrm{~Hz}, 3 \mathrm{H}), 1.67$ (tq, $J=7.2$, $7.2 \mathrm{~Hz}, 2 \mathrm{H}), 3.43$ (dt, $J=7.2,7.2 \mathrm{~Hz}, 2 \mathrm{H}), 6.79-6.90$ (br, 1H), $6.97(\mathrm{~s}, 1 \mathrm{H}), 7.47-7.50(\mathrm{~m}, 3 \mathrm{H}), 7.78-7.81(\mathrm{~m}, 2 \mathrm{H}) ;{ }^{13} \mathrm{C} \mathrm{NMR}$ (100 MHz, $\mathrm{CDCl}_{3}$, TMS) $\delta 11.4\left(\mathrm{CH}_{3}\right), 22.7\left(\mathrm{CH}_{2}\right), 41.2$ $\left(\mathrm{CH}_{2}\right), 99.2(\mathrm{CH}), 126.0(\mathrm{CH}), 126.9(\mathrm{C}), 129.1(\mathrm{CH}), 130.7$ (CH), 158.9 (C), 159.3 (C), 171.5 (C).

\section{References}

1. Nishiwaki, N.; Asahara, H. Carbamoylnitrile Oxide and Inverse Electron-Demand 1,3-Dipolar Cycloaddition. In Methods and Applications of Cycloaddition Reactions in Organic Syntheses; Nishiwaki, N., Ed.; John Wiley \& Sons: Hoboken, USA, 2014; pp 223-240. doi:10.1002/9781118778173.ch09

2. Torssell, K. B. G. Nitrile Oxides, Nitrones, and Nitronates in Organic Synthesis; VCH Publishers, Inc.: New York, USA, 1988; pp 55-74.

3. Nishiwaki, N.; Maki, A.; Ariga, M. J. Oleo Sci. 2009, 58, 481-484. doi:10.5650/jos.58.481

4. Nishiwaki, N.; Kobiro, K.; Kiyoto, H.; Hirao, S.; Sawayama, J.; Saigo, K.; Okajima, Y.; Uehara, T.; Maki, A.; Ariga, M. Org. Biomol. Chem. 2011, 9, 2832-2839. doi:10.1039/c0ob01005g

5. Nishiwaki, N.; Uehara, T.; Asaka, N.; Tohda, Y.; Ariga, M.; Kanemasa, S. Tetrahedron Lett. 1998, 39, 4851-4852. doi:10.1016/S0040-4039(98)00919-8

6. Nishiwaki, N.; Kobiro, K.; Hirao, S.; Sawayama, J.; Saigo, K.; Ise, Y.; Okajima, Y.; Ariga, M. Org. Biomol. Chem. 2011, 9, 6750-6754. doi:10.1039/c1ob05682d

7. Nishiwaki, N.; Kobiro, K.; Hirao, S.; Sawayama, J.; Saigo, K.; Ise, Y.; Nishizawa, M.; Ariga, M. Org. Biomol. Chem. 2012, 10, 1987-1991. doi:10.1039/c2ob06925c

8. Balasubramaniam, S.; Aidhen, I. S. Synthesis 2008, 3707-3738. doi:10.1055/s-0028-1083226

A review and references are cited in.

9. Parhi, A. K.; Franck, R. W. Org. Lett. 2004, 6, 3063-3065. doi:10.1021/ol0489752

Nitrile oxide having a Weinreb amide can be generated from cinnamic acid within five reaction steps; however, this protocol does not involve a conversion of $\mathrm{N}$-methylamide to the Weinreb amide.

10. Nagashima, H.; Ozaki, N.; Washiyama, M.; Itoh, K. Tetrahedron Lett. 1985, 26, 657-660. doi:10.1016/S0040-4039(00)89172-8

11. Katritzky, A. R.; Hoffmann, S.; Suzuki, K. ARKIVOC 2004, xii, 14-22. doi:10.3998/ark.5550190.0005.c03

12. Fang, C.; Qian, W.; Bao, W. Synlett 2008, 2529-2531. doi:10.1055/s-2008-1078218

13. Wu, X.; Larhed, M. Org. Lett. 2005, 7, 3327-3329. doi:10.1021/ol0512031

14. Dokli, I.; Gredičak, M. Eur. J. Org. Chem. 2015, 2727-2732. doi:10.1002/ejoc.201500051

15. Zhou, F.; Ding, K.; Cai, Q. Chem. - Eur. J. 2011, 17, 12268-12271. doi:10.1002/chem.201102459
16. Kovalenko, O. O.; Volkov, A.; Adolfsson, H. Org. Lett. 2015, 17, 446-449. doi:10.1021/ol503430t

17. Kawano, M.; Kiuchi, T.; Matsuo, J.-i.; Ishibashi, H. Tetrahedron Lett. 2012, 53, 432-434. doi:10.1016/j.tetlet.2011.11.067

18. Skillinghaug, B.; Sköld, C.; Rydfjord, J.; Svensson, F.; Behrends, M.; Sävmarker, J.; Sjöberg, P. J. R.; Larhed, M. J. Org. Chem. 2014, 79, 12018-12032. doi:10.1021/jo501875n

19. Shivakumar, S. B.; Basavaraju, Y. B.; Umesha, B.; Krishna, M. H.; Mallesha, N. Eur. J. Chem. 2014, 5, 424-429. doi:10.5155/eurjchem.5.3.424-429.1020

20. Tamura, M.; Nishimura, T.; Nishiwaki, N.; Ariga, M. Heterocycles 2004, 63, 1659-1665. doi:10.3987/COM-04-10085

21. Desai, V. G.; Naik, S. R.; Dhumaskar, K. L. Synth. Commun. 2014, 44, 1453-1460. doi:10.1080/00397911.2013.854916

22. Commercially available.

23. Tait, B.; Cullen, M. Methods of modulating cftr activity. PCT Int. Appl. WO 2014210159, Dec 31, 2014.

24. Maywald, V.; Freund, W.; Hamprecht, G.; Kuekenhoehner, T.; Plath, P.; Wuerzer, B.; Westphalen, K.-O. Carbonsäureamide. Eur. Pat. Appl. EP 418667, March 27, 1991.

25. Gao, P.; Li, H.-X.; Hao, X.-H.; Jin, D.-P.; Chen, D.-Q.; Yan, X.-B.; Wu, X.-X.; Song, X.-R.; Liu, X.-Y.; Liang, Y.-M. Org. Lett. 2014, 16, 6298-6301. doi:10.1021/ol503228x

26. Dikusar, E. A.; Potkin, V. I.; Pyatkevich, S. K. Russ. J. Gen. Chem. 2014, 84, 1701-1705. doi:10.1134/S1070363214090102

\section{License and Terms}

This is an Open Access article under the terms of the Creative Commons Attribution License (http://creativecommons.org/licenses/by/2.0), which permits unrestricted use, distribution, and reproduction in any medium, provided the original work is properly cited.

The license is subject to the Beilstein Journal of Organic Chemistry terms and conditions: (http://www.beilstein-journals.org/bjoc)

The definitive version of this article is the electronic one which can be found at: doi:10.3762/bjoc. 11.138 